\title{
Option Embedded Bonds: The Convertible Puttable Bond
}

\author{
Ghassem A. Homaifar \\ Middle Tennessee State University
}

\author{
Kevin M. Zhao \\ Middle Tennessee State University
}

We derive analytics of duration and convexity for the convertible puttable bond, which offers investors a significant upside potential embedded in the long call as well as downside protection of a long put. The inclusion of a long put in this bond makes the bond relatively more convex than a conventional pure bond, therefore, increasing both duration as well as convexity of this bond. We find that convexity of the convertible puttable bond is the highest when compared to other classes of convertibles as money managers pay a premium to acquire the convexity embedded in this hybrid financial instrument.

\section{INTRODUCTION}

The late nineties witnessed a proliferation of option embedded bonds such as callable, convertibles, puttable, callable convertibles, and convertible perpetual to name a few. This paper derives a mathematical expression for the duration of option embedded bonds namely, puttable bond. The price dynamics of this bond is different from that of the straight bond due to the inclusion of long put. Puttable bond is an interesting phenomenon developed by financial engineers as it exhibits an enormous amount of convexity not seen in any other classes of bonds. The price yield relationship for this class of bond is significantly different from other option embedded bonds, as yield is lower and the price is higher than that of the straight bonds. Therefore, investors pay a premium for the embedded long put that tends to hedge the underlying price of the bond at par in the worst case scenario. Over 561 companies have issued puttable bonds that give investors an opportunity to put the bond to the issuers at times of duress and rising interest rates environment as shown in Table 1.

Dunetz and Mahoney (1988), hereafter DM, developed duration and convexity for the callable bonds. Mehran and Homaifar (1993) provided an algorithm for the duration and convexity of the convertible bonds. Furthermore, Homaifar and Michello (2018) have developed analytics of duration and convexity of the callable convertible, which shows that duration and convexity combined underestimate (overestimate) the actual price change by $11 / 10$ basis points for plus/minus 100 basis points change in yield. In this paper, we derive a mathematical formula for duration and convexity of a convertible puttable which has the highest level of duration and convexity as compared to any other classes of convertible bonds developed in the last 20 years or so. ${ }^{1} \mathrm{We}$ find that duration of puttable bond is significantly greater than that of a pure convertible as investors have the option of delaying the conversion into common stock due to the inclusion of a long put option. The long put provides investors with a peace of mind that in the 
worst case scenario they can put the bond to the issuer at par. Furthermore, the long put embedded in this bond significantly increases the convexity of the bond well over the convexity of the other classes of the convertibles as a positive function of four parameters: namely, the price, duration, and convexity of the pure convertible as well as the gamma of the option.

\section{THEORETICAL REVIEW}

Most bonds issued in the market have option embedded features as they can be callable, convertible, extendable, puttable, and other options to name a few. Numerous studies have investigated the impact of duration and convexity on bond valuation with and without the embedded options features. ${ }^{2}$ Brennan and Schwartz (1988) maintain that issuing convertibles is intended to reduce interest expense initially while providing flexibility in future funding changes. Mahoney (1988) extended duration and convexity analysis to callable bonds. Yawitz (1988) demonstrates that convertible bonds possess positive convexity. ${ }^{3}$ Stein (1992) argues that the empirical evidence shows that highly rated companies issue straight debt, medium quality firms issue convertibles, and low rated and unrated companies issue equity. Mehran and Homaifar (1993), hereafter MH, provided mathematical expression for the duration and convexity of the convertible bond as well as formulating an optimum call policy for the issuers of convertibles. Homaifar et al (1994) also provided mathematical formulas for the duration and convexity of convertible preferred stock. The Jalan and Barone-Adesi (1995) study revealed that issuing convertibles provide interest tax shield until conversion as a backdoor equity, where issuing equity does not. The Mayers (2000) study reveals that issuing callable convertible bonds allows for sequential financing need. This finding is supported by the issuance of this type of debt by small high growth companies. Krishnaswami and Devrim (2008) argue that the agency cost of debt induces medium quality and high growth companies to issue convertibles over straight debt. The King and Mauer (2012) study reveal that issuing convertibles is intended to reduce agency cost of debt and equity. Fabozzi (2013) documented that callable bonds possess a negative convexity as this class of bond is called in the falling interest rate scenario that is advantageous to the issuer and disadvantageous to investors. Dorion et al (2014) demonstrated that when risk shifting is high, there is an increased incentive for the issuers to raise funds using convertible bonds.

The relationship between bond price and yield is non-linear due to inherent convexity in the bond pricing formula. ${ }^{4}$ Therefore, the convexity is a measure of the non-linear relationship between bond prices and changes in interest rates, or the second derivative of the bond price with respect to the changes in interest rates normalized by the price of the underlying bond.

This study extends the Homaifar and Michello (2018) duration and convexity of the callable convertible bond to a convertible puttable bond that gives investors upside potential embedded in a convertible bond as well providing investors with a downside protection of put option at par value. A convertible bond gives the bondholder the right to exchange the bond for a pre specified number of shares of common stock before the expiration date of the embedded long call. The convertible bond is converted if the stock price increases making conversion a positive net present value for the investors. The price dynamics of option-embedded bonds differs from that of a pure bond, as the embedded options reflect the price of the underlying stock as well as the changes in the required market yield for the underlying class of bond. The cash flows, as well as maturities of the option-embedded bonds, are unknown due to embedded options. Therefore, using simple duration and convexity of a pure bond is an inadequate proxy for the duration and convexity of convertible puttable bonds.

Convertible puttable bonds have a long call and the long put. For example, investors are motivated by profit as they are likely to convert the bonds into common stocks when it economically pays off to do so. This means investors are likely to forgo the coupon interest in the convertible bond in order to have an ownership interest in the issuing company's common stock. This scenario, while exposing investors to higher risk, is also likely to provide higher reward as well as future growth opportunities. In the event the stock continues to go up, investors would realize capital gains that are subject to lower capital gains tax rate. In contrast ordinary income that accrues to investors in the form of coupon interest is subject to a 
higher tax rate. Investors are also granted a long put that tends to hedge the price of the underlying bond below par value in the worst case scenario.

\section{PRICE DYNAMICS OF PUTTABLE BOND}

We define the puttable bond as a portfolio of long bond and long put. Investors pay a premium to acquire long put. Therefore, the puttable bond is a premium bond where the price is higher than that of the straight bond by the amount of premium for the embedded put option. Using simple duration and convexity of a straight bond is an inadequate proxy for duration and convexity of the puttable bond. The timing of the exercise of the put option is unknown as investors evaluate when to put the bond back to the issuer at par. At times of duress and rising interest rates, as well as likely downgrade of the issue, the put option becomes very valuable for investors to exercise. For example, consider a triple B investment grade puttable bond that gets downgraded to a single B due to a combination of macroeconomic or firm-specific events. While straight bonds may trade well below par value, the long put will provide downside protection below the par price. That means in the worst case scenario investors will be able to put the bond to the issuer at par.

Figure 1 illustrates the price-yield relationship for callable, convertible, and puttable bonds. As can be seen from the graph, the price of a puttable bond never falls below par value, while callable and convertible may trade below par as yield increases. The worst performing bond when yield rises is the callable bond as convertibles are somewhat protected by the long call. On the other hand, the convexity of the puttable bond is the highest of the three bond class followed by the pure convertibles and callable bonds respectively. As yield falls, callable bonds price will not go up beyond call price, while convertibles will enjoy the upside potential embedded in the long call of the convertible.

Convertibles offer downside protection when yield increases. While rising yield depresses stock and bond prices, the price of a convertible bond will not fall as much as a straight bond since the embedded long call price will go up as the interest rate goes up. Furthermore, convertible puttable bond price fall is mitigated by not only a long call but also a long put. The long put tends to act as a buffer to hedge the price of the bond at par value in the worst case scenario of a significant increase in the yield due to a macroeconomic reason or a firm-specific reason such as a downgrade of the bond. Price value of the change in the price of a bond or bond portfolio is captured by DV01 (dollar value of 1 basis point change in yield) of the bond portfolio. This metric measures the dollar price change in the value of the portfolio due to 1 basis point change in interest rates. ${ }^{5}$ 


\section{FIGURE 1 \\ PRICE AND YIELD RELATIONSHIP}

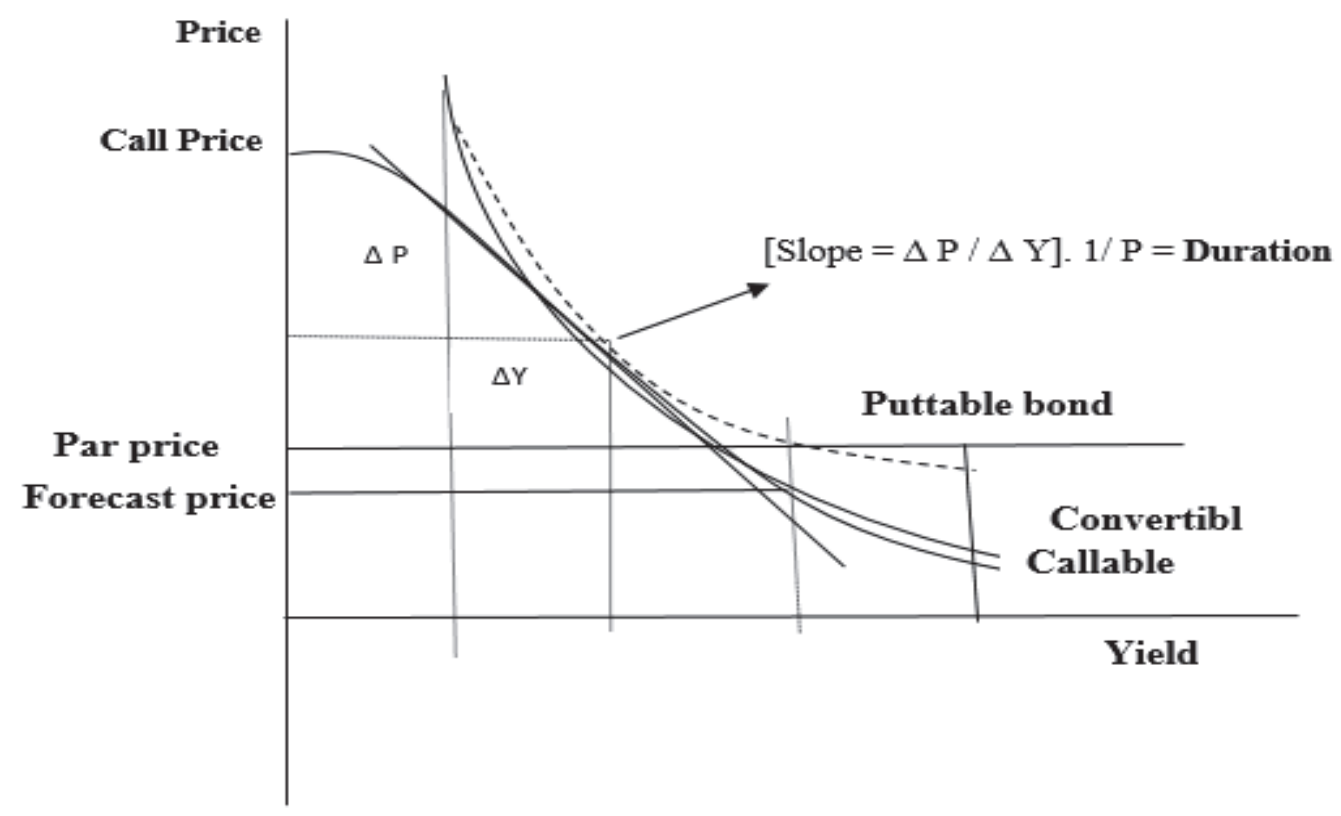

As can be confirmed from Figure 1, at times of rising interest rates, puttable bonds offer investors a hedge as the price will not fall below par value in the worst case scenario, making the bond very attractive to risk-averse investors. This bond offers investors both upside potential and downside protection of falling/rising interest rates.

Convertible bonds (CB) may be puttable in this case; this bond is defined as follows:

$\mathrm{CB}_{\mathrm{p}}=\mathrm{P}+\mathrm{CO}_{\mathrm{L}}+\mathrm{PU}_{\mathrm{L}}$

where: $\mathrm{P}$ is the price of a pure bond,

$\mathrm{CO}_{\mathrm{L}}$ is a long call granted to the investor,

$\mathrm{PU}_{\mathrm{L}}$ is a long put granted to the investor

Convertible puttable $\mathrm{CB}_{\mathrm{p}}$ can be redefined as:

$\mathrm{CB}_{\mathrm{p}}=\mathrm{CB}+\mathrm{PU}_{\mathrm{L}}$

Investors enjoy the benefits of long call as well as a long put for protection in the event of duress and rising interest rates. Therefore, the price dynamics of $\mathrm{CB}_{\mathrm{p}}$ is different from the other convertible types due to the long put extended to the investors.

Mehran and Homaifar (1993) extended Dunetz and Mahoney's (1988) duration and convexity of callable bonds to convertible bonds as a portfolio of pure bond and a long call option as follows.

$\mathrm{D}_{\mathrm{cb}}=\mathrm{D} \times \mathrm{P} / \mathrm{P}_{\mathrm{cb}} \times 1 /(1-\Delta)$

Taking derivative of equation 2 with respect to a change in yield:

$\mathrm{dCB}_{\mathrm{p}} / \mathrm{dk}=\partial \mathrm{CB} / \partial \mathrm{k}+\left(\partial \mathrm{PU}_{\mathrm{L}} / \partial \mathrm{CB}\right)(\partial \mathrm{CB} / \partial K)$ 
Define $\quad \Delta_{\mathrm{p}}=\left(\partial \mathrm{PU}_{\mathrm{L}} / \partial \mathrm{CB}\right)$ and

$\mathrm{dCB} / \mathrm{dK}=\mathrm{D}_{\mathrm{cb}} \times \mathrm{P}_{\mathrm{cb}}$

Subsisting equations 3, 5, and 6 into 4 and rearranging terms:

$\mathrm{D}_{\mathrm{cp}}=\mathrm{D} \times \mathrm{P} / \mathrm{P}_{\mathrm{cp}} \times\left(1+\Delta_{\mathrm{P}}\right) /(1-\Delta)$

where: $\mathrm{D}$ is the duration of straight bond

$\mathrm{P}_{\mathrm{cb}}$ is the price of the convertible bond

$\Delta_{\mathrm{p}}$ is the delta of the long put (between 0 to -1)

$\Delta$ is the delta of the long call (between 0 to +1 )

$\mathrm{P}_{\mathrm{cp}}$ is the price of the convertible puttable

When delta is zero for a long call, it is -1 for the long put as the duration of the puttable bond is zero as bondholders are likely to put the bond to the issuer at par provided that the issuer is in a position to pay the creditors without default. However, as the delta of long put approaches to -.8 and the delta of the long call is slightly positive say .25 . In this case, the puttable convertible has duration that is less than that of pure convertible bond by a factor that is equal to $(1-.80) /(1-.25)$. That is the last term in Equation 7 as the ratio of one plus the two deltas $\left(1+\Delta_{\mathrm{p}}\right) /\left(1-\Delta_{\mathrm{L})}\right.$. Therefore, an inclusion of a long put significantly decreases the duration of the puttable bond as compared to a pure convertible. At the limit when the delta of the long call is +1 , the delta of the long put is zero. Therefore, duration of the convertible puttable at the limit is approximately equal to that of the underlying stock that is infinite. In the initial DM (1988) derivation, duration of the callable bond is defined as a portfolio of a long bond and a short call as follows:

$\mathrm{D}_{\mathrm{c}}=\mathrm{D} \times \mathrm{P} / \mathrm{P}_{\mathrm{ca}} \times(1-\Delta)$

where: $\mathrm{D}$ is the duration of the straight bond

$\mathrm{P}$ and $\mathrm{P}_{\mathrm{ca}}$ are the prices of straight bond and price of callable bond respectively.

$\mathrm{D}_{\mathrm{c}}$ duration of the callable bond

Duration of a callable bond in Equation 8 as derived by DM approaches to zero when the delta is 1 as the bond is called. Once delta is zero, duration of the callable bond is equal to that of the pure bond. However, once the bond is called, it disappears from the balance sheet of the issuing company. Therefore, its convexity is also had to be equal to zero. This is not the case as DM (1988) convexity is none zero (actually negative) once delta is equal to 1 .

The convexity of the convertible puttable bond is derived by the second derivative of Equation 4 using differential calculus as follows:

$\partial^{2} \mathrm{P}_{\mathrm{cp} /} \partial \mathrm{K}^{2}=\partial^{2} \mathrm{P}_{\mathrm{cb}} / \partial \mathrm{K}^{2}+\partial^{2} \mathrm{PU}_{\mathrm{L} /} \partial^{2}{ }_{\mathrm{cb} X}\left(\partial \mathrm{P}_{\mathrm{cb}} / \partial \mathrm{k}\right)^{2}+\partial \mathrm{PU}_{\mathrm{L} /} \partial_{\mathrm{cb}} \mathrm{X} \partial^{2} \mathrm{P}_{\mathrm{cb}} / \partial \mathrm{K}^{2}$

Substituting equation 5 and 6 into 9 and rearranging terms will yield the convexity of the convertible puttable as follows:

$\left.\mathrm{C}_{\mathrm{cp}}=\mathrm{P}_{\mathrm{cb}} / \mathrm{P}_{\mathrm{cp} \mathrm{x}[} \mathrm{C}_{\mathrm{cb}}\left(1+\Delta_{\mathrm{p}}\right)+\boldsymbol{\Gamma}_{\mathbf{P}} \times \mathrm{P}_{\mathrm{cb}} \times \mathrm{D}_{\mathrm{cb}}^{2}\right]$

Substituting convexity of the convertible bond $\mathrm{C}_{\mathrm{cb}}$ as derived by Mehran and Homaifar (1993) into 10 that is as follows and rearranging.

$\mathrm{C}_{\mathrm{cb}}=1 /(1-\Delta) \times \mathrm{P} / \mathrm{P}_{\mathrm{cb}}\left[\mathrm{C}_{\mathrm{p}}+\boldsymbol{\Gamma}_{\mathrm{L}} \times \mathrm{P}_{\mathrm{cb}} \times \mathrm{D}_{\mathrm{cb}}^{2}\right]$ From MH (1993) 
$\mathrm{C}_{\mathrm{cp}=} \mathrm{P}_{\mathrm{cb}} / \mathrm{P}_{\mathrm{cp} \times\{}\left[\mathrm{P} / \mathrm{P}_{\mathrm{cb}}\left(\mathrm{C}_{\mathrm{p}}+\boldsymbol{\Gamma}_{\mathbf{L}} \times \mathrm{P}_{\mathrm{cb}} \times \mathrm{D}_{\mathrm{cb}}^{2}\right]\left(1+\Delta_{\mathrm{p}}\right) /(1-\Delta)+\boldsymbol{\Gamma}_{\mathbf{p}} \times \mathrm{P}_{\mathrm{cb}} \times \mathrm{D}_{\mathrm{cb}}^{2}\right\}$

where: $\mathrm{C}_{\mathrm{cb}}$ is the convexity of the convertible bond

$\Gamma_{\mathrm{P}}$ is the gamma of the long put that is always positive

$\Gamma_{\mathrm{L}}$ is the gamma of the long call that is positive

As I reiterated earlier, the convertible puttable bond has the highest level of convexity at any value of delta of both embedded options as compared to any other types of convertible bonds. For example, when the delta of long call is equal to 1 , the delta of long put is zero and the convexity of the convertible puttable is infinite. Meaning that the bond will be converted into common stock. However, when delta of long call is zero while that of long put is -1 , the convexity of the convertible puttable is finite that is equal to the last term in equation $10, \Gamma_{\mathbf{P}} \times \mathrm{P}_{\mathrm{cb}} \times \mathrm{D}_{\mathrm{cb}}^{2}$. It is the inclusion of the long put that makes this bond highly convex, as the underlying call and put options delta changes with the change in the value of the bond. Furthermore, equation 10 shows that the convexity of the puttable is directly and positively correlated with the 3 parameters in equation 10, namely: the gamma of the long put, price of convertible bond, and duration of the convertible bond. The convertible puttable has higher convexity than the pure convertible bond. As the convertible puttable offers investors' higher yield at a given price all else remaining the same. Furthermore, this bond offers investors' highest price at a given yield all else remaining the same as shown in the figure 1 . The marginal convexity increase due to an inclusion of a long put is simply equal to the last three terms in the equation $11\left(\boldsymbol{\Gamma}_{\mathbf{P}} \times \mathrm{P}_{\mathrm{cb}} \times \mathrm{D}_{\mathrm{cb}}^{2}\right)$; namely the gamma of the long put, price of convertible bond, and duration of the convertible squared. The marginal increase in the convexity due to inclusion of the long call in equation 11 is equal to $\left(\boldsymbol{\Gamma}_{\mathbf{L}} \times \mathrm{P}_{\mathrm{cb}} \times \mathrm{D}_{\mathrm{cb}}^{2}\right)$. A survey of the convertibles in the Bloomberg financials identified 3000 convertibles that are classified in Table 1 . Nearly half of all that is 1469 issues are pure convertibles denominated in various currencies. There are 561 issues of convertible puttable. As table 1 reveals there are 9 different classes of convertibles mostly in triple digits. Financial engineers have been hard at work in developing these option embedded bonds that can appeal to different classes of investors with the wide varying risk-return profile. Analysis of the various convertible bonds can increase investors understanding and appreciation of these bonds and is likely to bridge the enormous gap between Wall Street and that of the academic community in the measurement, control, and mitigation of risks involved in this complex financial innovation.

\section{IMPLICATIONS AND CONCLUDING REMARKS}

We derive analytics of duration and convexity for the convertible puttable bond. This is a unique bond that offers investors upside potential as well as a downside protection. Generally speaking, investors pay a premium for the long call embedded in this bond as well as paying a premium to hedge the price at par value. The inclusion of a long put in this bond makes the bond relatively more convex than a conventional pure bond. Therefore, increasing duration as well as convexity of when rates are falling for this bond as compared to any other classes of convertibles. When delta is zero for the long call as it is -1 for the long put, duration of the puttable bond is equal to zero. In such case bondholders are likely to put the bond to the issuer at par, provided that the issuer can redeem the issue without default. Therefore, an inclusion of a long put when the issuer is in duress and likely to get downgraded decreases the duration of the puttable bond as compared to a pure convertible. At the limit when the delta of the long call is +1 , the delta of long put is zero. Therefore, duration of the convertible puttable at the limit is equal to that of the underlying stock that is infinite.

Convertible puttable is a unique financial instrument having characteristics and price dynamics of stocks and bonds. There remains a great deal of potential for investigating this hybrid financing and investment vehicle. We find that convexity of the convertible puttable bond is the highest when compared to other classes of convertibles as money managers are willing to pay a premium to acquire the significant convexity embedded in this hybrid financial instrument. We find that the convexity of the puttable bond is 
positively correlated with the price, duration, and convexity of the pure convertible bond as well as the gamma of the long call option. Investors are motivated by economics as they are likely to exercise the long call to convert the bond into a predetermined share of stock when the stock is rising. On the other hand, the company may force the conversion for other than economic reasons such as window dressing the balance sheet. ${ }^{6}$ While long put is intended to minimize the risk for the investors as it enables investors to put the issue back to the issuer in the event of significant increase in yield due to downgrade. However, credit risk is always present as the issuing company may not be able to redeem the debt at par compliment of a long put. This is an empirical issue to be investigated over time.

TABLE 1

\section{TYPES OF CONVERTIBLES}

\begin{tabular}{|lr|}
\hline Maturity Type & \\
\hline Convertible & 1,469 \\
Conv/Call & 216 \\
Conv/Call/Perp & 136 \\
Conv/Perp & 344 \\
Conv/Put & 561 \\
Conv/Put/Call & 257 \\
Conv/Sink & 14 \\
Conv/Call Sink & 2 \\
Conv/Put/Call/SF & 1 \\
& $\mathbf{3 0 0 0}$ \\
\hline
\end{tabular}

\section{ENDNOTES}

1. See table 1 for various classes of convertibles.

2. See Black and Scholes (1973).

3. Convexity is defined as the 2 nd derivative of the bond with respect to a change in yield divided by the price of a bond.

4. See Fabozzi (2013) and Yawitz (1988).

5. Dollar value of 1 basis point DV01 is equal to the product of the 3 factors; modified duration, price, and $+/-1$ bps change in yield.

6. Ingersoll (1977) reveals that the median firm in his sample of 179 issues of convertible bonds waited until the conversion value was greater than its call price by 43 percent before forcing conversion. Therefore, leading him to conclude that the firms in his sample did not pursue an optimum call policy. 


\section{REFERENCES}

Black, F., \& Scholes, M. (1973).The pricing of options and corporate liabilities. Journal of Political Economy, 8(1), 637-659.

Brennan, M.J., Schwartz, E. S. (1988). The case for convertibles. Journal of Applied Corporate Finance, 1(2), 55-64.

Dorian, C., François, P., Grass, G., Jeanneret, A. (2014). Convertible Debt and Shareholder Incentives. Journal of Corporate Finance, 24, 38-56.

Dunetz, M.L., Mahoney, J.M. (1988). Using duration and convexity in the analysis of callable bonds. Financial Analysts Journal, 44(3), 53-72.

Fabozzi. F. (2013). Bond markets analysis and strategies. Pearson Publishing 8th Edition.

Homaifar, G., Ehsani, H., \& Lee, J.T. (1994). The duration and convexity of the preferred stocks: an extension. Applied Financial Economics, 4, 323-327.

Homaifar, G., \& Michello, F.(2018). The duration and Convexity of the preferred stocks: an extension. Applied Economics Letters. DOI: 10. 1080/13504851.2018/1502862.

Ingersoll, J. (1977b). An examination of corporate call policy on convertible securities. Journal of Finance, 32: 463-478.

Jalan, P., \& Barone-Adesi, G. (1995). Equity financing and corporate convertible bond policy. Journal of Banking and Finance, 19, 187-206.

King, T.D., \& Mauer, D.C. (2014). Determinants of corporate call policy for convertible bonds. Journal of Corporate Finance, 24, 112-134.

Krishnaswami, S., \& D. Yaman, (2008). The role of convertible bonds in alleviating contracting costs. Quarterly Review of Economics and Finance, 48: 792-816.

Macaulay, F.R. (1938). Some theoretical problems suggested by the movements of interest rates, bond yields and stock prices in the United States since 1856. National Bureau of Economic Research. New York.

Mayer, D. (2000). Convertible bonds: matching financial and real options. Journal of Applied Corporate Finance, 13(1), 8-21.

Mehran, J., \& Homaifar, G. (1993). Analytics of duration and convexity for bonds with embedded options: The case of convertibles. Journal of Business Finance and Accounting, 20(1), 107-113.

Stein, C. J. (1992). Convertible bonds as backbone equity financing. Journal of Financial Economics, 32 , $3-21$.

Yawitz, J.B. (1988). Convexity an introduction. Institute of Financial Analyst, 137-162. (The CFA Candidate Reading). 